\title{
Oxygen Potentials and Defect Chemistry in Nonstoichiometric $(\mathrm{U}, \mathrm{Pu}) \mathrm{O}_{2}$
}

\author{
Masato Kato \\ Japan Atomic Energy Agency \\ Japan
}

\section{Introduction}

Nuclear reactors have been developed to secure stable long-term energy supply. Light water reactors (LWRs) have been operated on a commercial basis in many countries. In LWRs, uranium oxide is used as a fuel. Plutonium which is another element that can be used for generating nuclear energy is produced by a nuclear reaction during burning of uranium oxide fuel and it is extracted from spent fuel when they are reprocessed. Uranium and plutonium mixed oxide $\mathrm{s}(\mathrm{MOX})$ fuels containing Pu of less than and more than $15 \%$ have been developed for LWRs and fast reactors, respectively. These oxides are fabricated into pellets by powder metallurgy. In the pellet production process, dimensions, density and oxygen-to-metal $(\mathrm{O} / \mathrm{M})$ ratio of the pellets are managed as important fuel specifications. The $\mathrm{O} / \mathrm{M}$ ratio significantly affects various physical properties. Therefore it is essential to understand the $\mathrm{O} / \mathrm{M}$ ratio dependence on physical properties for analyzing irradiation behavior.

Uranium and plutonium mixed oxide $(\mathrm{U}, \mathrm{Pu}) \mathrm{O}_{2}$, which is used in nuclear fuels, is a substitutional solid solution compound having the $\mathrm{CaF}_{2}$ type fluorite structure as shown in Fig.1 (Markin \& Street, 1967; Sari et al., 1970; Kato \& Konashi, 2009). (U,Pu) $\mathrm{O}_{2}$ is stable in a wide range region of hyper- and hypo-stoichiometric compositions. The $\mathrm{O} / \mathrm{M}$ ratio in nonstoichiometric $(\mathrm{U}, \mathrm{Pu}) \mathrm{O}_{2}$ is dominated by the numbers of oxygen vacancies and interstitial oxygen atoms. The stoichiometry of $(\mathrm{U}, \mathrm{Pu}) \mathrm{O}_{2}$ significantly affects various physical properties such as lattice parameter, melting temperature, and thermal conductivity. (Kato et al., 2011a) Therefore many studies on O/M ratio dependence of oxygen potential have been carried out by various methods. The oxygen potential of $(\mathrm{U}, \mathrm{Pu}) \mathrm{O}_{2}$ drastically changes with a slight $\mathrm{O} / \mathrm{M}$ change in the near stoichiometric region. Such drastic change may cause a large uncertainty in oxygen potential measurements, and the measured data may be scattered in a range of more than $\pm 100 \mathrm{~kJ} / \mathrm{mol}$.

Oxygen potentials have been measured by various methods including the E.M.F. and the gas equilibrium method using thermo-gravimetric measurements. The E.M.F. method cannot be applied to measurements above $1473 \mathrm{~K}$ temperature, and it is difficult to use it to determine slight $\mathrm{O} / \mathrm{M}$ changes in the near stoichiometric region. In the thermo-gravimetric measurements, various gas mixtures like $\mathrm{CO} / \mathrm{CO}_{2}$ and $\mathrm{H}_{2} \mathrm{O} / \mathrm{H}_{2}$ are employed for controlling the oxygen potential. The oxygen potential region control depends on the kind of gases used for the measurements. So, it is crucial to understand the relationships among 
the used gas types, oxygen potential and $\mathrm{O} / \mathrm{M}$ ratio. Furthermore, for the thermogravimetric measurements as well, it is very difficult to determine the stoichiometric composition in the high temperature region because of the $\mathrm{O} / \mathrm{M}$ ratio continuous variation for the near stoichiometric composition.

In previous studies (Kato et al., 2009a, 2011b 2011c), the stoichiometric compositions in $(\mathrm{U}, \mathrm{Pu}) \mathrm{O}_{2}$ have been determined based on defect chemistry. The relationship between oxygen partial pressure and deviation $x$ from stoichiometric composition has been analyzed in non-stoichiometric oxides. Kosuge (1993) used statistical thermodynamics considerations for description of non-stoichiometric compounds, and Karen (2006) reported a point-defect scheme for them. Recently their methods have been applied for nonstoichiometric $(\mathrm{U}, \mathrm{Pu}) \mathrm{O}_{2}$, and experimental data, accurately measured in the near stoichiometric region, were analyzed as a function of temperature. In this report the measurement data and the measurement technique were reviewed and analysis results based on defect chemistry were summarized.

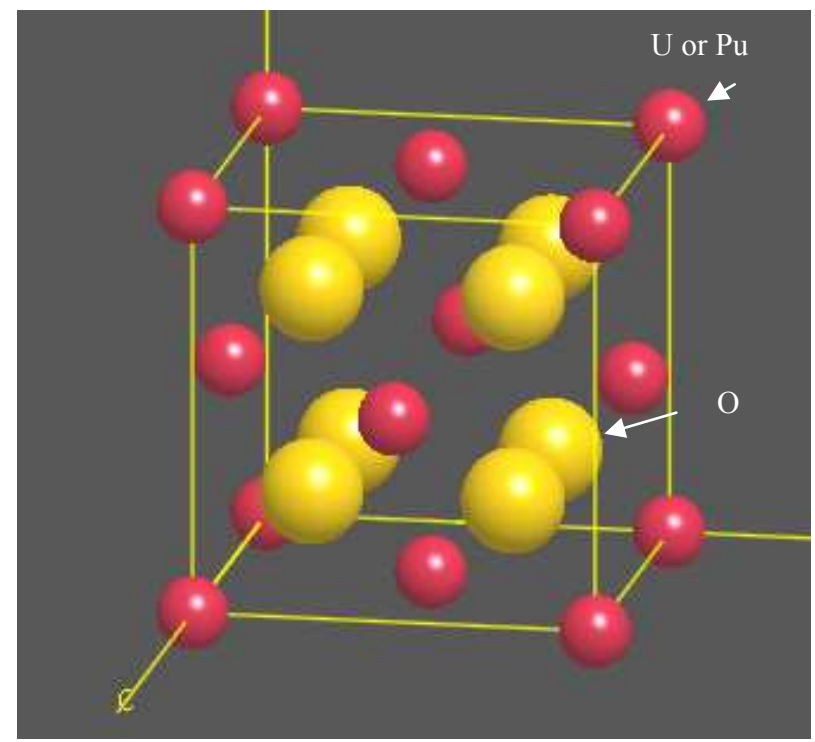

Fig. 1. $\mathrm{CaF}_{2}$ type fluorite structure

\section{Experimental data of oxygen potential in $(\mathrm{U}, \mathrm{Pu}) \mathrm{O}_{2}$}

The measurement data of $(\mathrm{U}, \mathrm{Pu}) \mathrm{O}_{2}$ are listed in Table 1. The relationships between oxygen potential and $\mathrm{O} / \mathrm{M}$ ratio were obtained as functions of temperature and Pu content. Almost all data that were measured in the 1960's and 1970's had large uncertainty. Recently Kato et al. $(2005,2009 b, 2011 b, 2011 c)$ accurately obtained a large number of data in (U,Pu) $\mathrm{O}_{2}$ by insitu analysis. Fig. 2 shows the measurement data as functions of $\mathrm{O} / \mathrm{M}$ ratio and $\mathrm{Pu}$ content. The data were measured in both regions of hyper- and hypo-stoichiometric compositions and they increased with $\mathrm{Pu}$ content. Fig.3 shows the oxygen potential $\Delta \overline{\mathrm{G}}_{\mathrm{O}_{2}}$ of $\left(\mathrm{U}_{0.8} \mathrm{Pu}_{0.2}\right) \mathrm{O}_{2 \pm x}$. The oxygen potential is calculated by eqs.(1)-(2). 


\begin{tabular}{|c|c|c|c|c|}
\hline References & $\mathrm{Pu}(\%)$ & O/M & Temp. (K) & Data points \\
\hline Woodley, 1981 & 10 & $1.96-2.00$ & $1273-1473$ & 17 \\
\hline Sørensen,1976 & 10 & $1.98-1.99$ & $1222-1674$ & 12 \\
\hline Markin \& McIver, 1965 & 11 & $1.95-2.08$ & $1073-1373$ & 45 \\
\hline Kato et al., 2011b & 12 & $1.988-2.0408$ & $1673-1873$ & 76 \\
\hline Chilton \& Kirkham, 1976 & 15 & $2.002-2.106$ & $1518-1823$ & 24 \\
\hline Javed, 1973 & 20 & $1.920-1.989$ & $1273-1973$ & 20 \\
\hline Sørensen,1976 & 20 & $1.99-2.00$ & $1359-1674$ & 17 \\
\hline Mari et al., 1977 & 20 & $1.96-1.99$ & $757-1276$ & 24 \\
\hline Tetenbaum, 1974 & 20 & $1.92-1.96$ & $2150-2550$ & 25 \\
\hline Kato et al., 2009b,2011c & 20 & $1.979-2.0088$ & $1473-1873$ & 105 \\
\hline Vasudeva Rao et al., 2006 & 21 & $1.964-2.00$ & $1073-1473$ & 53 \\
\hline Chilton \& Edwards, 1980 & 23 & $1.980-2.030$ & $1523-1822$ & 114 \\
\hline Woodley \&Adamson, 1985 & 25 & $1.90-2.00$ & $1222-1674$ & 68 \\
\hline Vasudeva Rao et al., 2006 & 28 & $1.975-2.00$ & $1073-1473$ & 19 \\
\hline Markin \& McIver, 1965 & 30 & $1.86-2.06$ & $1073-1373$ & 39 \\
\hline Kato et al., 2005, 2011c & 30 & $1.964-2.028$ & $1273-1873$ & 153 \\
\hline Chilton \& Kirkham, 1976 & 31 & $1.99-2.07$ & $1518-1823$ & 52 \\
\hline Woodley, 1981 & 40 & $1.90-2.00$ & $1273-1473$ & 23 \\
\hline
\end{tabular}

Table 1. Measurement data of $(\mathrm{U}, \mathrm{Pu}) \mathrm{O}_{2}$

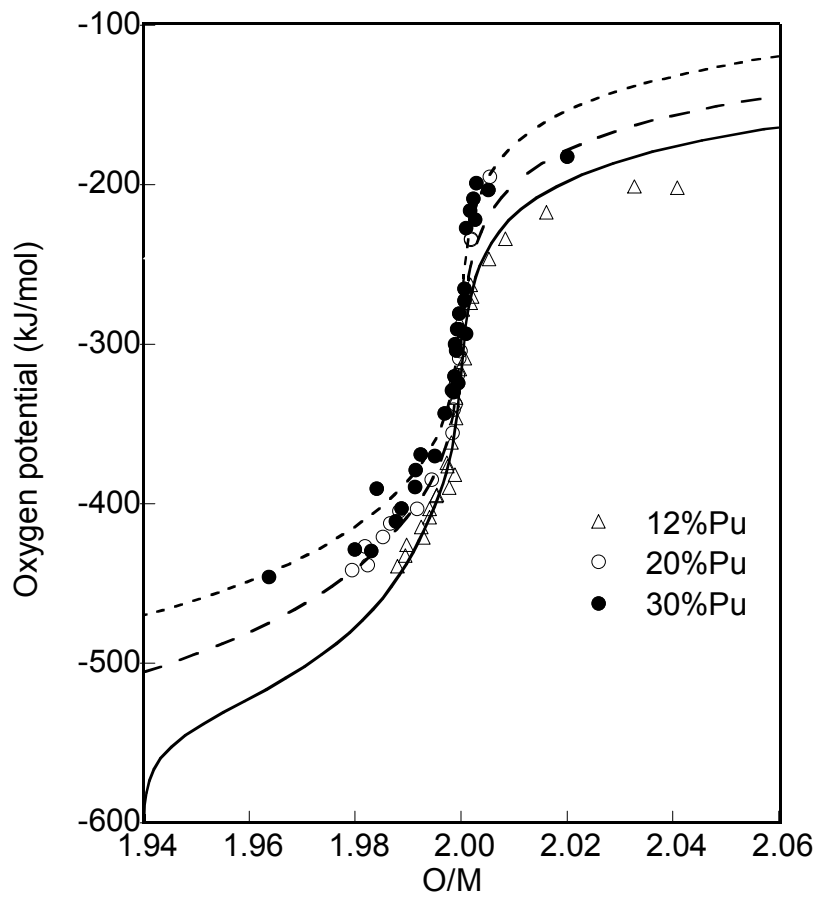

Fig. 2. Oxygen potential at $1873 \mathrm{~K}$ as function of Pu content and $\mathrm{O} / \mathrm{M}$ ratio (Kato et al., 2009b, 2011c) 


$$
\begin{gathered}
\Delta \bar{G}_{O_{2}}=R T \ln P_{o_{2}} \\
\Delta \bar{G}_{O_{2}}=\Delta \bar{H} O_{O_{2}}-T \cdot \Delta \bar{S}_{O_{2}},
\end{gathered}
$$

Here $R$ is the gas constant $(8.3145 \mathrm{~J} / \mathrm{K} / \mathrm{mol}), T$ is absolute temperature $\Delta \overline{\mathrm{H}}_{\mathrm{O}_{2}}$ is partial molecular enthalpy of $\mathrm{O}_{2}$ and $\Delta \overline{\mathrm{S}}_{\mathrm{O}_{2}}$ is partial molecular entropy of $\mathrm{O}_{2}$. Eq.(2) predicts that the oxygen potential varies in a linear manner as a function of temperature. The data, however, have an inflection point at hypo-stoichiometric composition of $2.00>0 / M>1.95$ as shown in Fig.3. This change is consistently explained based on defect chemistry as mentioned later.

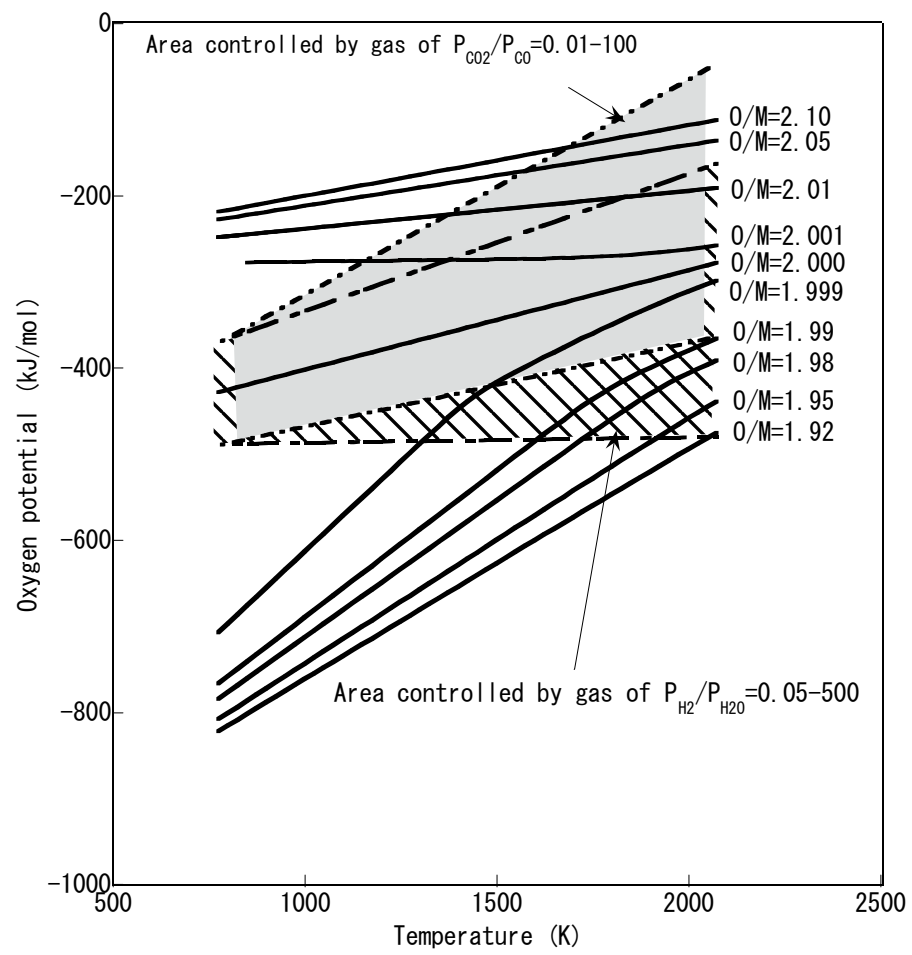

Fig. 3. Oxygen potential of $\left(\mathrm{U}_{0.8} \mathrm{Pu}_{0.2}\right) \mathrm{O}_{2 \pm x}$

\section{Measurement techniques}

The measurements in previous studies were carried out by the E.M.F. and gas equilibrium methods. The former can accurately measure oxygen potentials, but the measurement data are only limited to a temperature range between $1123 \mathrm{~K}$ and $1423 \mathrm{~K}$. Besides, it is 
difficult to determine the $\mathrm{O} / \mathrm{M}$ ratio for the near stoichiometric composition. In the gas equilibrium method, a thermo-gravimeter is employed, which can measure a small deviation of the $\mathrm{O} / \mathrm{M}$ ratio. Here, the measurement technique by the gas equilibrium method is explained. A thermo-gravimetry and differential thermal analysis system (TGDTA) was put in glove box and used to measure oxygen potential (Kato et al., 2005, 2009b, $2011 b, 2011 c)$. The oxygen partial pressure of the flowing gas was monitored at the inlet and outlet of the apparatus using stabilized zirconia oxygen sensors. Gas mixtures of $\mathrm{H}_{2} / \mathrm{H}_{2} \mathrm{O}$ and $\mathrm{CO} / \mathrm{CO}_{2}$ were used for controlling the measurement atmosphere. The oxygen partial pressures are determined by the reactions of eqs.(3) and (4) in each gas system.

$$
\begin{gathered}
\mathrm{CO}+1 / 2 \mathrm{O}_{2} \leftrightarrow \mathrm{CO}_{2} \\
\Delta \overline{\mathrm{S}}_{\mathrm{O}_{2}} \leftrightarrow \mathrm{H}_{2} \mathrm{O}
\end{gathered}
$$

The regions controlled by both gas mixtures are shown by shaded and gray areas, respectively, in Fig.3. The $\mathrm{H}_{2} / \mathrm{H}_{2} \mathrm{O}$ mixture gives control at lower oxygen potential. Previously, Kato et al. (2011b, 2011c) used the $\mathrm{H}_{2} / \mathrm{H}_{2} \mathrm{O}$ mixture to measure hyper- and hypo-stoichiometric $(\mathrm{U}, \mathrm{Pu}) \mathrm{O}_{2}$. Considering the reaction of eq.(4), the equilibrium may be expressed by a free energy of formation, $\Delta G_{f}$, given by eqs.(5) and (6).

$$
\begin{gathered}
\Delta G_{f}=-R T \cdot \ln \frac{P_{\mathrm{H}_{2} \mathrm{O}}}{P_{\mathrm{H}_{2}} \cdot P_{\mathrm{O}_{2}}{ }^{1 / 2}} \\
\Delta G_{f}=-246440+54.8 \cdot T
\end{gathered}
$$

The $P_{\mathrm{O}_{2}}$ values in the flowing gas from the measurement apparatus were monitored at $973 \mathrm{~K}$ with the stabilized zirconia sensors at the inlet and the outlet. The ratio of $P_{\mathrm{H}_{2}} / P_{\mathrm{H}_{2} \mathrm{O}}$ at the outlet sensor can be determined by eqs.(5) and (6), and $P_{\mathrm{O}_{2}}$ at measurement temperatures was calculated under the assumption that the ratio of $P_{\mathrm{H}_{2}} / P_{\mathrm{H}_{2} \mathrm{O}}$ at the sensor position was the same at any sampling position. Therefore, the oxygen potential can be determined by controlling the ratio of $P_{\mathrm{H}_{2}} / P_{\mathrm{H}_{2} \mathrm{O}}$ in the flowing gas.

\section{Statistical thermodynamics of point defects}

The relation between $\mathrm{x}$ and $P_{o_{2}}$ in non-stoichiometric compounds was analyzed based on statistical thermodynamics of point defects in a previous report (Kosuge, 1993) and eq.(7) was derived.

$$
\frac{P_{o_{2}}(x)}{P_{o_{2}}(0)}=1+\frac{x^{2}+x \sqrt{x^{2}+4 C^{2}}}{2 C^{2}}
$$

Here $P_{o_{2}}(0)$ represents $P_{o_{2}}$ at the stoichiometric composition and $C$ is the intrinsic fraction of defects. Eq.(7) can be applied in the near stoichiometric region. Data for $(\mathrm{U}, \mathrm{Pu}) \mathrm{O}_{2}$ in the near stoichiometric region have been obtained by Kato et al. (2011b, 2011c). Curves of 
$P_{o_{2}}(0) / P_{o_{2}}(x)$ versus $\mathrm{x}$ are shown in Fig.4. Eq. (7) was a least square fit using the experimental $x$ and $P_{\mathrm{O} 2}(x)$ as a parameter of temperature and the relationship between $\mathrm{x}$ and $\mathrm{P}_{\mathrm{O} 2}(\mathrm{x})$ was determined. The $P_{\mathrm{O} 2}(x)$ and $C$ were evaluated from Fig.4; they are shown in Table 2. Temperature dependence on oxygen potential is given by eq. (2). Therefore, oxygen potential of stoichiometric $\left(\mathrm{U}_{0.8} \mathrm{Pu}_{0.2}\right) \mathrm{O}_{2}$ was obtained from the data in Table 1 according to the following equation.

$$
\Delta \bar{G}_{O_{2}}=-517.5 \times 10^{3}+116.5 \cdot T
$$

Eq.(8) shows that $\Delta \bar{H}_{O_{2}}$ and $\Delta \bar{S}_{O_{2}}$ at stoichiometric composition are $-517.5 \mathrm{~kJ} / \mathrm{mol}$ and 116.5 $\mathrm{J} / \mathrm{mol} / \mathrm{K}$, respectively. Kato et al. (2011c) summarized their data in MOX containing 12, 20 and $30 \% \mathrm{Pu}$. The $\Delta \bar{H}_{\mathrm{O}_{2}}$ values were almost the same and the $\Delta \bar{S}_{\mathrm{O}_{2}}$ values decreased with $\mathrm{Pu}$ content. In the present work the oxygen potential of $\left(\mathrm{U}_{1-y} \mathrm{Pu}_{y}\right) \mathrm{O}_{2.00}$ dependence on $\mathrm{Pu}$ content was estimated by eq.(9).

$$
\Delta \bar{G}_{O_{2}}=-521.2 \times 10^{3}-(117.8 \cdot y+92.1) \cdot T
$$

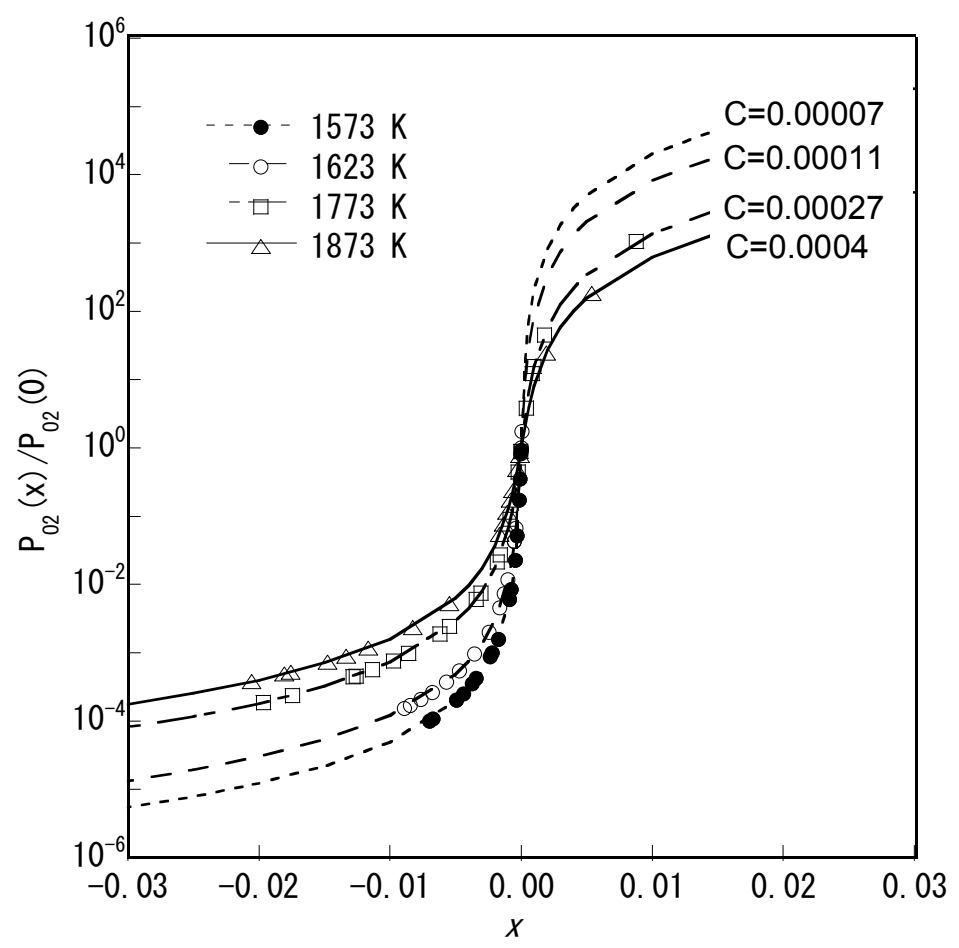

Fig. 4. Curves of $P_{o_{2}}(0) / P_{o_{2}}(x)$ versus $x$ in $\left(\mathrm{U}_{0.8} \mathrm{Pu}_{0.2}\right) \mathrm{O}_{2 \pm x}$ 


\begin{tabular}{|l|l|l|}
\hline Temperature $(\mathrm{K})$ & $P_{o_{2}}(0)(\mathrm{atm})$ & $\mathrm{C}$ \\
\hline 1573 & $7.93 \mathrm{E}-12$ & 0.00007 \\
\hline 1623 & $2.68 \mathrm{E}-11$ & 0.00011 \\
\hline 1773 & $6.88 \mathrm{E}-10$ & 0.00027 \\
\hline 1873 & $4.48 \mathrm{E}-09$ & 0.00040 \\
\hline
\end{tabular}

Table 2. $\mathrm{P}_{\mathrm{o}_{2}}(0)$ and $\mathrm{C}$ in $\left(\mathrm{U}_{0.8} \mathrm{Pu}_{0.2}\right) \mathrm{O}_{2}$

The intrinsic fraction of defects $C$ may be described by the following equation:

$$
C=A \cdot \exp \left(-\frac{E}{2 \kappa T}\right)
$$

where $E$ is the formation energy for intrinsic ionization, $A$ is a constant and $\kappa$ is the Boltzmann constant. $E$ was estimated to be $2.9 \mathrm{eV}$ from the relationship between $C$ and $1 / T$. The value of $E$ predicts the band gap energy. The band gap energies of $\mathrm{UO}_{2}$ andPuO 2 were reported to be 2.7 and $2.5 \mathrm{eV}$, respectively (Nakamura \& Fujino, 1986; Naito et al., 1980). The value of $E$ in this work was slightly higher compared with other data.

\section{Defect equilibria - Kröger-Vink diagram}

The nonstoichiometry of various compounds has been analyzed using Kröger - Vink diagrams (Kröger \& Vink, 1957; Kofstad, 1972; Sørensen, 1981; Karen, 2009). In this section, the notation of Kröger - Vink was used. (Kröger \& Vink, 1957) Deviation $x$ in (U,Pu) $\mathrm{O}_{2 \pm x}$ is proportional to $P_{o} \pm 1 / n$, where $n$ is a characteristic number identifying the defect (Kofstad, 1972; Sørensen, 1981). Relationships between $x$ and $P_{o}$ in $\left(\mathrm{U}_{0.8} \mathrm{Pu}_{0.2}\right) \mathrm{O}_{2 \pm x}$ were analyzed, and are shown in Fig.5. The slopes of $n=-4$, and -2 were observed in hypo-stoichiometric MOX, and that of $n=+2$ was observed in hyper-stoichiometric MOX. It was reported that $n=-4$ changed to $n=-3$ for $\left(\mathrm{U}_{0.7} \mathrm{Pu}_{0.3}\right) \mathrm{O}_{2 \pm x}$.

Then, defect reactions of eqs. (11)-(16) are considered for defect equilibria in $\left(\mathrm{U}_{0.8} \mathrm{Pu}_{0.2}\right) \mathrm{O}_{2 \pm x}$.

$$
\begin{gathered}
O^{\times}{ }_{O}+M_{P u}^{\times} \rightarrow\left(V_{O}^{*} M_{P u}^{\prime}\right)^{\bullet}+e^{\prime}+\frac{1}{2} O_{2} \\
2 O_{O}^{\times}+O_{2} \rightarrow\left(2 O_{i}^{a} 2 O_{i}^{b} 2 V_{O}^{* \bullet}\right)^{\prime}+h^{\bullet} \\
N i l l \rightarrow e^{\prime}+h^{\bullet} \\
O_{O}^{\times} \rightarrow V_{O}^{\bullet \bullet}+O_{i}^{\prime \prime} \\
O_{O}^{\times} \rightarrow V_{o}^{\bullet \bullet}+2 e^{\prime}+\frac{1}{2} O_{2} \\
\frac{1}{2} O_{2} \rightarrow O_{i}^{\prime \prime}+2 h^{\bullet}
\end{gathered}
$$




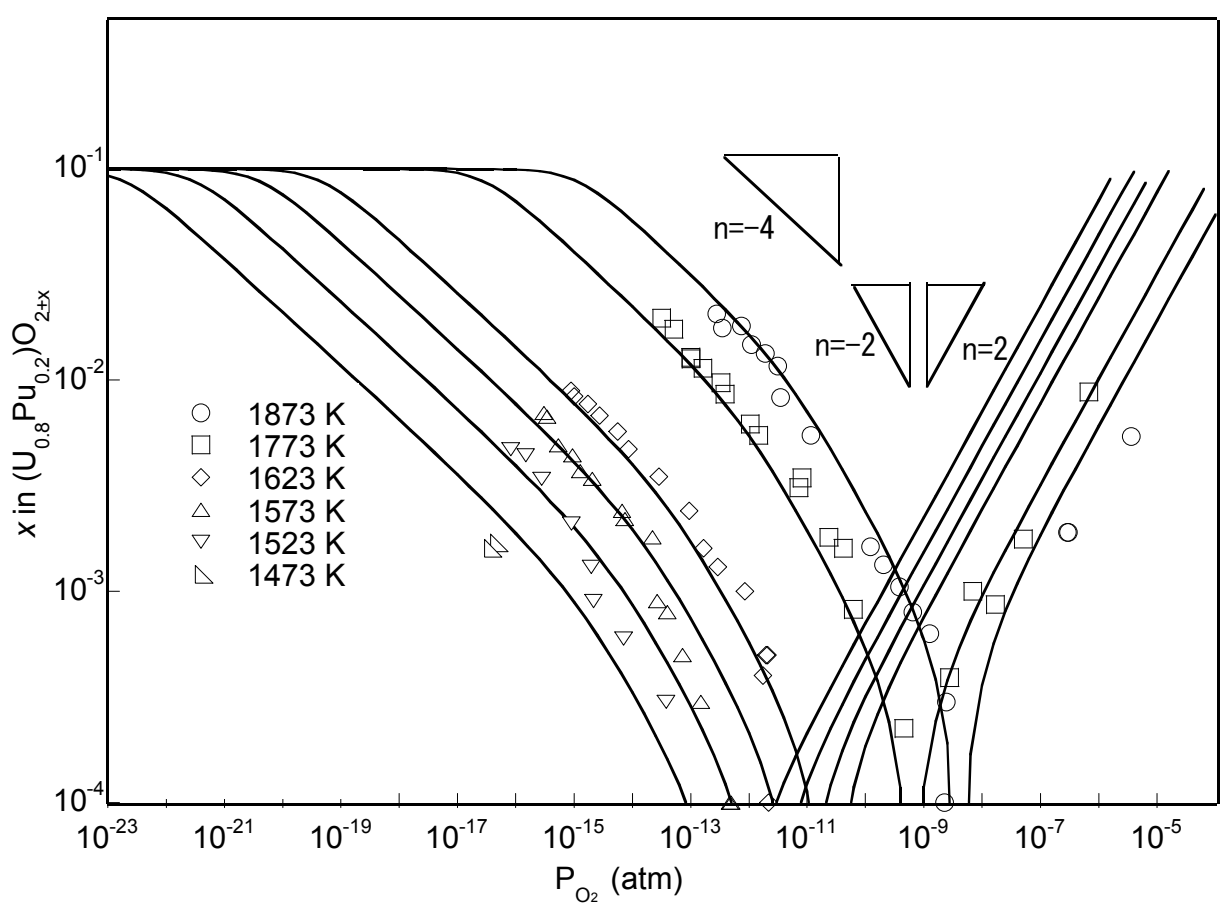

Fig. 5. The $P_{o_{2}}$ versus $x$ in $\left(\mathrm{U}_{0.8} \mathrm{Pu}_{0.2}\right) \mathrm{O}_{2 \pm x}$

The equibrium constants in the defect reactions (11)-(16) are described as Eqs.(17)-(22), respectively.

$$
\begin{gathered}
K_{\mathrm{Re}}=\left\lfloor\left(V_{O}^{\bullet \bullet} P u^{\prime}\right)^{\bullet} \mid P u^{\prime}\right] P_{O_{2}}^{1 / 2} \\
K_{O x}=\left[\left(2 O_{i}^{a} 2 O_{i}^{b} 2 V_{O}^{\bullet \bullet}\right)^{\prime}\right]\left[h^{\bullet}\right] P_{O_{2}}^{-1} \\
K_{i}=\left[h^{\bullet} \mid\left[e^{\prime}\right]\right. \\
K_{F}=\left\lfloor V_{O} \cdot \bullet\left[O_{i}^{\prime \prime}\right]\right. \\
K_{V o}=\left\lfloor V_{O} \cdot \bullet \mid\left[e^{\prime}\right]^{2} P_{O_{2}}^{1 / 2}\right. \\
K_{O i}=\left[O_{i}^{\prime \prime}\right]\left[h^{\bullet}\right]^{2} P_{O_{2}}^{-1 / 2}
\end{gathered}
$$

Two types of diagrams were proposed depending on the dominant defects of the near stoichiometric region; these are Frenkel defects or intrinsic defects. 
Region I: Near stoichiometric region

In the case of $(\mathrm{U}, \mathrm{Pu}) \mathrm{O}_{2 \pm x}$, it was reported that intrinsic ionization of eq.(13) is dominant in the near stoichiometric region. So, eq.(20) can be written as

$$
\left[h^{\bullet}\right]=\left[e^{\prime}\right]=K_{i}^{1 / 2} .
$$

When inserting eq.(23) into eqs.(21) and (22), $\left|V_{O} \cdot{ }^{*}\right|$ and $\left|O_{i}^{\prime \prime}\right|$ are given by eqs.(24) and (25).

$$
\begin{aligned}
& {\left[V_{O}^{\cdot \cdot}\right]=\frac{K_{V_{0}}}{\left[e^{\prime}\right]^{2}} P_{O_{2}}^{-1 / 2}=\frac{K_{V o}}{K_{i}} P_{O_{2}}^{-1 / 2}} \\
& {\left[O_{i}^{\prime \prime}\right]=\frac{K_{O i}}{\left[h^{\bullet}\right]^{2}} P_{O_{2}}^{1 / 2}=\frac{K_{O i}}{K_{i}} P_{O_{2}}^{1 / 2}}
\end{aligned}
$$

If the deviation $x$ is given by

$$
x=\left[V_{O} \cdot \bullet\right] \text { or }\left[O_{i}^{\prime \prime}\right],
$$

the value of $n$ is +2 and -2 in the near stoichiometric region, which is consistent with the relationship shown in Fig.5.

Region II: Reducing region

In the defect reaction of eq.(11), the electro-neutrality condition is given by

$$
\left[\left(V_{O}^{*} P u^{\prime}\right)^{\bullet}\right]=\left[e^{\prime}\right] \text {. }
$$

When inserting eq.(27) into eq.(17), $\left|V_{o} \cdot\right|$ can be written by

$$
\left[V_{O} \cdot \cdot\right]=\left[\left(V_{O}^{*} P u^{\prime}\right)^{\bullet}\right]=K_{\mathrm{Re}}^{1 / 2} P_{O_{2}}^{-1 / 4} \text {. }
$$

The value of $\mathrm{n}$ is derived as -4 .

Region III: Oxidizing region

In the defect reaction of eq.(12), the electro-neutrality condition is given by

$$
\left[\left(2 O_{i}^{a} 2 O_{i}^{b} 2 V_{o}^{*}\right)^{\prime}\right]=\left[h^{\cdot}\right]
$$

When inserting eq.(29) into eq.(18), $\left\lfloor O_{i}^{\prime \prime}\right\rfloor$ can be written by

$$
\left[O_{i}^{\prime \prime}\right]=2\left[\left(2 O_{i}^{a} 2 O_{i}^{b} 2 V_{O}^{* *}\right)^{\prime}\right]=2 K_{O i}{ }^{1 / 2} P_{O_{2}}^{1 / 2}
$$

The value of $\mathrm{n}$ is derived as +2 .

The measured data shown in Fig.5 were fitted by eqs.(24), (25), (29) and (30), and the equilibrium constants were estimated as a function of temperatures. Eqs.(31)-(34) were obtained from the relationship between equilibrium constants and $1 / T$. 


$$
\begin{gathered}
K^{\prime}=\frac{K_{V_{0}}}{K_{i}}=493.4 \exp \left(\frac{-372.0 \times 10^{3}}{R T}\right) \\
K^{\prime \prime}=\frac{K_{O i}}{K_{i}}=5.095 \times 10^{-5} \exp \left(\frac{175.6 \times 10^{3}}{R T}\right) \\
K_{\mathrm{Re}}=80420 \exp \left(\frac{-515.0 \times 10^{3}}{R T}\right) \\
K_{O x}=4.14 \times 10^{-8} \exp \left(\frac{291.0 \times 10^{3}}{R T}\right)
\end{gathered}
$$

Eqs. (24), (25), (29), (30) and (31)-(34) could represent the Kröger - Vink diagram as shown in Fig.6. The calculation results were consistent with the measured data. In addition, the equilibrium constants, $K_{i}, K_{F}, K_{V o}$ and $K_{O_{i}}$, were obtained as eqs.(35)-(38).

$$
\begin{gathered}
K_{i}=106400 \exp \left(\frac{-286.0 .0 \times 10^{3}}{R T}\right) \\
K_{F}=0.2006 \exp \left(\frac{-226.5 \times 10^{3}}{R T}\right) \\
K_{V_{o}}=5.248 \times 10^{7} \exp \left(\frac{-658.0 \times 10^{3}}{R T}\right) \\
K_{O i}=4.41 \times 10^{-3} \exp \left(\frac{5.0 \times 10^{3}}{R T}\right)
\end{gathered}
$$

Eqs.(35)-(38) can predict the transformation energy of defects. The predicted values are shown in Table 3 and they had close agreement with other data.

The $\mathrm{O} / \mathrm{M}$ ratio of $(\mathrm{U}, \mathrm{Pu}) \mathrm{O}_{2}$ is an important parameter for development of nuclear fuels. So, it is essential to know the $\mathrm{O} / \mathrm{M}$ ratio as functions of temperature and oxygen potential. If deviation $\mathrm{x}$ is equivalent to $\left[V_{o} \cdot \cdot\right]$ and $\left[O_{i}^{\prime \prime}\right]$, the $\mathrm{O} / \mathrm{M}$ ratio can be written by

$$
\mathrm{O} / \mathrm{M}=2.00-\left[V_{O}^{\cdot \cdot}\right]+\left\lfloor O_{i}^{\prime \prime}\right] \text {. }
$$

In the hypo-stoichiometric region, $\left|V_{O} \cdot{ }^{*}\right|$ is described by eqs.(24) and (28). In addition, it is assumed that ${ }_{V_{O}} \cdot{ }^{*} \mid$ is limited by eq. $(40)$ because the valence of $\mathrm{Pu}$ is +3 .

$$
\left\lfloor V_{O}^{\bullet \cdot \bullet}\right]=0.01 \text {. }
$$

Therefore, $\left[V_{o} \cdot \mid\right.$ is estimated by the following equation using eqs.(24), (28) and (40).

$$
\left[V_{O} \cdot \boldsymbol{*}\right]=\left[\left(\frac{K_{V_{O}}}{K_{i}} P_{O_{2}}^{-1 / 2}\right)^{-3}+\left(K_{\mathrm{Re}}^{1 / 2} P_{O_{2}}^{-1 / 4}\right)^{-3}+(0.01)^{-3}\right]^{-1 / 3}
$$


$\left[O_{i}^{\prime \prime}\right]$ is estimated by the following equation using eqs.(25).

$$
\left[O_{i}^{\prime \prime}\right]=\left[\left(\frac{K_{O_{i}}}{K_{i}} P_{O_{2}}^{1 / 2}\right)^{-2}+\left(2 K_{O_{i}}^{1 / 2} P_{O_{2}}^{1 / 2}\right)^{-2}\right]^{-1 / 2}
$$

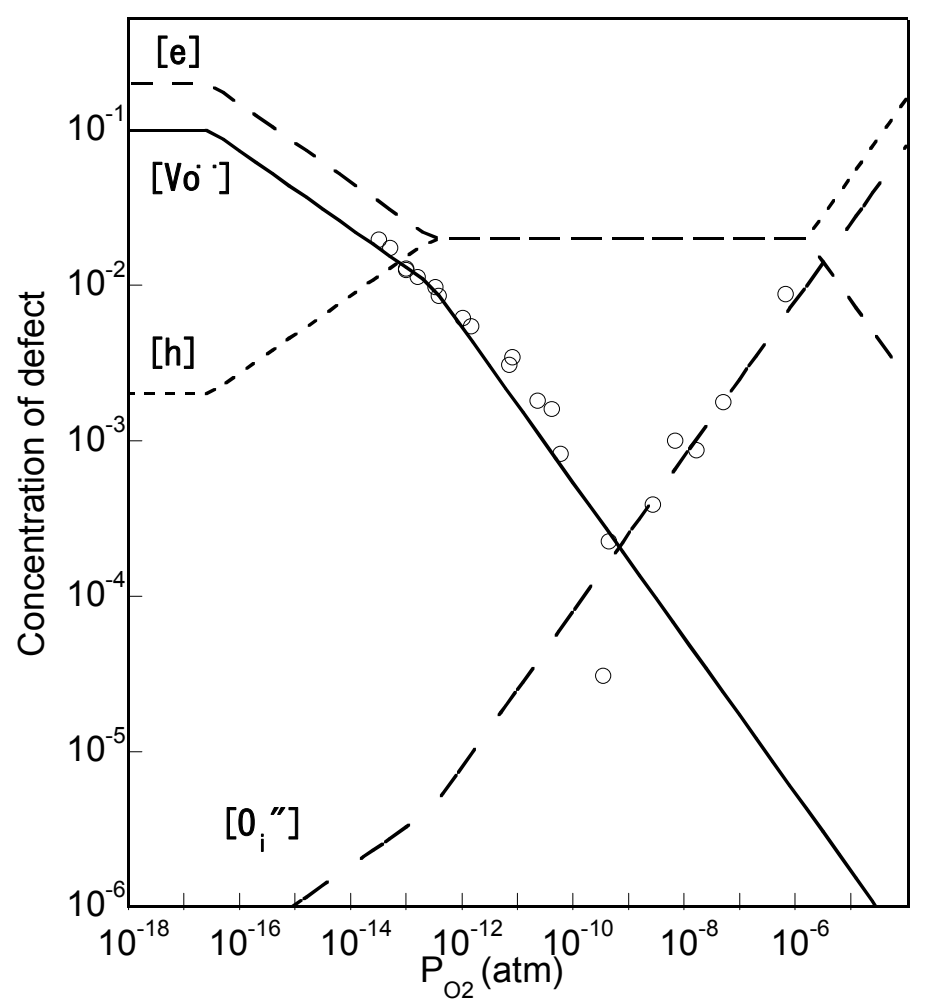

Fig. 6. Calculation results of defect concentration at $1773 \mathrm{~K}$ in $\left(\mathrm{U}_{0.8} \mathrm{Pu}_{0.2}\right) \mathrm{O}_{2 \pm x}$

When inserting eqs.(38) and (39) into eq.(36), the $\mathrm{O} / \mathrm{M}$ ratio can be represented. The calculation results are shown in Fig.5; lines as functions of temperature and oxygen partial pressure were in good agreement with the experimental data. The figure shows that the dominate defect changed with temperature in hypo-stoichiometric oxide with constant $\mathrm{O} / \mathrm{M}$ ratio. So, two forms of eq.(2) were obtained, and the curve of the temperature dependence of the oxygen potential had a flexion point as shown in Fig 3.

In the reducing region, the relationship of $n$ changed from -4 to -3 with Pu content. The $n=-3$ was observed in $\left(\mathrm{U}_{0.7} \mathrm{Pu}_{0.3}\right) \mathrm{O}_{2-\mathrm{x}}$. In this region, the defect reaction of (43) was assumed for describing the Kröger - Vink diagram. The defect concentration was given by eq.(44) and the relationship of $n=-3$ was obtained. 


$$
\begin{gathered}
2 O^{\times}{ }_{O}+2 M_{P u}^{\times} \rightarrow\left(2 V_{O}^{*} 2 M_{P u}^{\prime}\right)^{\bullet}+2 e^{\prime}+\frac{1}{2} O_{2} \\
{\left[V_{O}^{* \bullet}\right]=2\left[\left(2 V_{O}^{\bullet \bullet} 2 P u^{\prime}\right)^{\bullet \cdot}\right]=\left(2 K_{\mathrm{Re}}\right)^{1 / 3} P_{o_{2}}^{-1 / 3}}
\end{gathered}
$$

\begin{tabular}{|c|c|c|c|}
\hline Defect reaction & Material & $\begin{array}{c}\text { Transformation } \\
\text { energy of defect } \\
(\mathrm{eV})\end{array}$ & References \\
\hline \multirow{3}{*}{$\mathrm{Nill} \rightarrow e^{\prime}+h^{\bullet}$} & MOX & 3.0 & This work \\
\hline & $\mathrm{UO}_{2}$ & 2.1 & $\begin{array}{c}\text { Nakamura \& Fujino, } \\
1986\end{array}$ \\
\hline & $\mathrm{PuO}_{2}$ & 2.5 & Stan \& Cristea, 2005 \\
\hline \multirow[b]{2}{*}{$O_{O}^{\times} \rightarrow V_{O}^{\ddot{*}}+O_{i}^{\prime \prime}$} & MOX & 2.3 & This work \\
\hline & $\mathrm{UO}_{2}$ & 5.3 & $\begin{array}{c}\text { Nakamura \& Fujino, } \\
1986\end{array}$ \\
\hline \multirow{2}{*}{$O_{O}^{\times} \rightarrow V_{o}^{\ddot{*}}+2 e^{\prime}+\frac{1}{2} O_{2}$} & MOX & 6.8 & This work \\
\hline & $\mathrm{PuO}_{2}$ & 4.8 & Stan \& Cristea, 2005 \\
\hline \multirow[b]{2}{*}{$\frac{1}{2} O_{2} \rightarrow O_{i}^{\prime \prime}+2 h^{\bullet}$} & MOX & -0.05 & This work \\
\hline & $\mathrm{UO}_{2}$ & -0.2 & $\begin{array}{c}\text { Nakamura \& Fujino, } \\
1986 \\
\end{array}$ \\
\hline$O_{O}^{\times}+P u^{\times} \rightarrow\left(V_{O}^{* \bullet} P u^{\prime}\right)^{\bullet}+P u^{\prime}+\frac{1}{2} O_{2}$ & MOX & 5.3 & This work \\
\hline \multirow[b]{2}{*}{$2 O_{O}^{\times}+O_{2} \rightarrow\left(2 O_{i}^{a} 2 O_{i}^{b} 2 V_{O}^{* \bullet}\right)^{\prime}+U^{\bullet}$} & MOX & -3.0 & This work \\
\hline & $\mathrm{UO}_{2}$ & -2.6 & $\begin{array}{c}\text { Nakamura \& Fujino, } \\
1986\end{array}$ \\
\hline
\end{tabular}

Table 3. Comparison of transformation energy of defects

\section{Application to O/M control}

The $\mathrm{O} / \mathrm{M}$ ratio is one of the most important parameters in controlling a reactor using $(\mathrm{U}, \mathrm{Pu}) \mathrm{O}_{2}$ nuclear fuels. The fuels are used in the hypo-stoichiometric composition range to control the fuel and cladding chemical interaction. The $\mathrm{O} / \mathrm{M}$ ratio is adjusted in a sintering process which is carried out in an $\mathrm{Ar} / \mathrm{H}_{2}$ gas mixture atmosphere. In this atmosphere, the oxygen potential is determined by eqs. (1), (5) and (6). According to the equations, the oxygen partial pressure is determined by controlling the $P_{\mathrm{H}_{2}} / P_{\mathrm{H}_{2} \mathrm{O}}$ ratio and temperature.

The $\mathrm{O} / \mathrm{M}$ ratios of $(\mathrm{U}, \mathrm{Pu}) \mathrm{O}_{2}$ are represented by the derived eqs.(36), (38) and (39) and are shown in Fig.7 as functions of $P_{\mathrm{H}_{2}} / P_{\mathrm{H}_{2} \mathrm{O}}$ and temperatures. In the low temperature region of less than $1000 \mathrm{~K}$, the $\mathrm{O} / \mathrm{M}$ ratio is almost 2.0, despite $P_{\mathrm{H}_{2}} / P_{\mathrm{H}_{2} \mathrm{O}}$ ratio in the atmosphere. In this temperature range, it is almost impossible to adjust to a hypo-stoichiometric composition in the $\mathrm{H}_{2} / \mathrm{H}_{2} \mathrm{O}$ gas atmosphere. In the higher temperature range, the $\mathrm{O} / \mathrm{M}$ ratio decreases with increasing $P_{\mathrm{H}_{2}} / P_{\mathrm{H}_{2} \mathrm{O}}$ ratio. The $\mathrm{O} / \mathrm{M}$ ratio approaches 1.65 and remains at almost 2.00 at $1973 \mathrm{~K}$ in the atmosphere of $P_{\mathrm{H}_{2}} / P_{\mathrm{H}_{2} \mathrm{O}}=200$ and $P_{\mathrm{H}_{2}} / P_{\mathrm{H}_{2} \mathrm{O}}=2$, respectively. The $(\mathrm{U}, \mathrm{Pu}) \mathrm{O}_{2}$ fuels with various $\mathrm{O} / \mathrm{M}$ ratios may be produced using the relationships of Fig.7. 
However, the $\mathrm{O} / \mathrm{M}$ ratio increases during the cooling process after the sintering. So, control of cooling rate may be needed to obtain low $\mathrm{O} / \mathrm{M}$ fuel. Furthermore, the kinetics evaluation of $\mathrm{O} / \mathrm{M}$ change is essential to get adjustment to an accurate $\mathrm{O} / \mathrm{M}$ ratio.

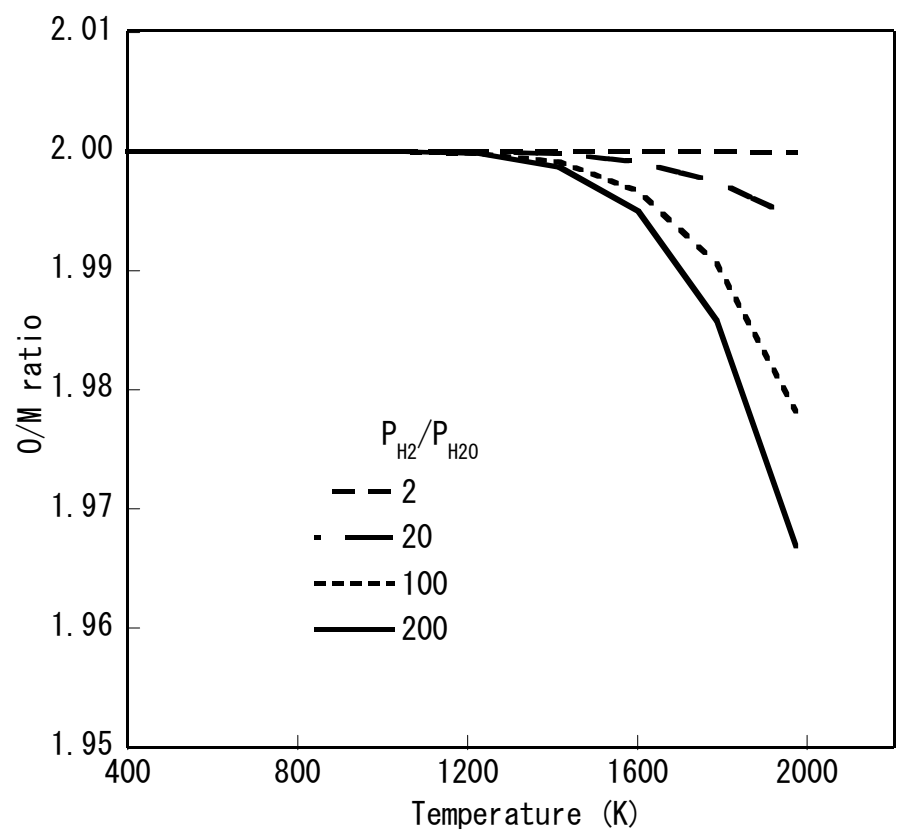

Fig. 7. O/M variation of $\left(\mathrm{U}_{0.8} \mathrm{Pu}_{0.2}\right) \mathrm{O}_{2 \pm x}$ as a function of $P_{\mathrm{H}_{2}} / P_{\mathrm{H}_{2} \mathrm{O}}$

\section{Summary}

In $(\mathrm{U}, \mathrm{Pu}) \mathrm{O}_{2}$ the oxygen nonstoichiometry significantly affects various physical properties, so it is essential to know the oxygen potential as functions of $\mathrm{O} / \mathrm{M}$ ratio and temperatures for development of nuclear fuels. Many studies on oxygen potential have been carried out. However, the data are scattered because of the difficulty of measurement.

Recently, data were accurately measured by the gas equilibrium method using thermogravimetry. The data were analysed based on defect chemistry. The $\mathrm{O} / \mathrm{M}$ ratio varies continuously with changing oxygen potential for the near stoichiometric composition, so it is very difficult to determine the stoichiometric composition in experiments. The stoichiometric composition was determined by analysis of statistical thermodynamics of point defects. The analysis results predicted the band gap energy of $2.9 \mathrm{eV}$. Additionally, the data were analyzed by a Kröger - Vink diagram. The defect reactions were assumed from experimental data, concentrations of defects were evaluated as functions of temperature and oxygen partial pressure, and the equation for the $\mathrm{O} / \mathrm{M}$ ratio was derived. The derived equation can represent the $\mathrm{O} / \mathrm{M}$ ratio as functions of temperature and $P_{\mathrm{H}_{2}} / P_{\mathrm{H}_{2} \mathrm{O}}$ and can be applied for the sintering process to adjust the $\mathrm{O} / \mathrm{M}$ ratio. 
In the development of nuclear fuels, it is also important to understand the oxygen potential dependence on $\mathrm{Pu}, \mathrm{Am}$ and $\mathrm{Np}$ contents. $\mathrm{Pu}$ content is known to increase the oxygen potential. Several groups have investigated the effect of $\mathrm{Am}$ and $\mathrm{Np}$ addition in $(\mathrm{U}, \mathrm{Pu}) \mathrm{O}_{2}$ (Kato et al., 2009;Nakamichi et al., 2011). They found that the addition of Am caused the oxygen potential to increase, but $\mathrm{Np}$ addition did not affect the oxygen potential. The derived equation for $\mathrm{O} / \mathrm{M}$ ratio will be extended to represent the $\mathrm{O} / \mathrm{M}$ ratio dependence on $\mathrm{Pu}$ and Am contents in future fuels.

\section{Acknowledgement}

The author is grateful to Dr. K. Konashi and Dr. S. Nagai for his fruitful discussions. The authors are pleased to acknowledge Mr. T. Sunaoshi, Mr. T. Tamura and Mr. H. Uno for his collaboration

\section{References}

Chilton, G. R. \& Edwards, J. (1980). Oxygen Potentials of $\mathrm{U}_{0.77} \mathrm{Pu}_{0.23} \mathrm{O}_{2 \pm \mathrm{X}}$ in the temperature range 1523 - 1822K, United Kingdom Atomic Energy Authority Northern Division Report, ND-R-276(W)

Chilton, G. R. \& Kirkham, I. A. (1976).The Determination of Oxygen Potentials of Hyperstoichiometric U-Pu Dioxides in the Temperature Range 1500 - 1800K, Plutonium 1975, pp.171-180

Edwards, J.; Wood, R. N. \& Chilton, G. R. (1985). Oxygen Potentials of Uranium-Plutonium Oxides in the Near Stoichiometric Region, Journal of Nuclear Materials, Vol.130, pp.505-512

Javed, N. A. (1973). Thermodynamic Behavior of (U, Pu) Mixed-Oxide Fuels, Journal of Nuclear Materials, Vol.47, pp.336-344

Karen, P. (2006). Nonstoichiometry in oxides and its control, Journal of Solid State Chemistry, Vol.179, pp.3167-3183

Kato, M.; Tamura, T.; Konashi, K. \& Aono, S. (2005). Oxygen Potentials of Plutonium and Uranium Mixed Oxide, Journal of Nuclear Materials, Vol.344, p.p.235-239

Kato, M. \& Konashi, K. (2009). Lattice parameters of (U,Pu,Np,Am) $\mathrm{O}_{2-x}$, Journal of Nuclear Materials, Vol.385, pp. 117-121, 2009

Kato, M. ; Konashi, K. \& Nakae, N. (2009a). Analysis of oxygen potential of $\left(\mathrm{U}_{0.7} \mathrm{Pu}_{0.3}\right) \mathrm{O}_{2 \pm x}$ and $\left(\mathrm{U}_{0.8} \mathrm{Pu}_{0.2}\right) \mathrm{O}_{2 \pm x}$ based on point defect chemistry, Journal of Nuclear Materials, Vol.389, pp.164-169

Kato, M.; Tamura, T. \& Konashi, K. (2009b). Oxygen potentials of Mixed Oxide Fuels for Fast Reactors, Journal of Nuclear Materials, Vol.38, pp.419-423

Kato, M. ; Maeda, K.; Ozawa, T.; Kashimura, M.\& Kihara, Y. (2011a). Physical Properties and Irradiation Behavior Analysis of $\mathrm{Np}$ - and Am-Bearing MOX Fuels, Journal of Nuclear Science and Technology, Vol.48, pp.1-8

Kato, M. ; Takeuchi, K. ; Uchida, T. ; Sunaoshi, T. \& Konashi, K. (2011b). Oxygen potential of $\left(\mathrm{U}_{0.88} \mathrm{Pu}_{0.12}\right) \mathrm{O}_{2 \pm x}$ and $\left(\mathrm{U}_{0.7} \mathrm{Pu}_{0.3}\right) \mathrm{O}_{2 \pm x}$ at high temperatures of 1673-1873K, Journal of Nuclear Materials, Vol. 414, p.p.120-125 
Kato, M.; Nakamichi, S.; Takeuchi, K. \& Sunaoshi, T. (2011c). Measurement of oxygen potential in $\left(\mathrm{U}_{0.8} \mathrm{Pu}_{0.2}\right) \mathrm{O}_{2 \pm x}$ at high temperatures of 1773 , and $1873 \mathrm{~K}$, CALPHAD; Computer Coupling of Phase Diagram and Thermochemistry, Vol.35, p.p. 623-626

Kofstad, P. (1972). Nonstoichiometry, Diffusion and Electrical Conductivity in Binary Metal Oxides, John Wiley and Sons, New York

Kosuge, K. (1993). Chemistry of Non-Stoichiometric Compounds, Oxford University, Press, New York, pp. 21-26

Kröger, F.A. \& Vink, H. (1957). Solid State Physics, Academic Press, New York, 1957

Mari, C.M.; Pizzini, S.; Manes, L. \& Toci, F. (1977). A Novel Approach to the Oxygen Activity Microdetermination of Oxides by EMF Measurements, Journal of Electrochemistry Society Vol.56, pp.1831-1836

Markin, T.L. (1967). The Plutonium-Oxygen and Uranium-Plutonium-Oxygen Systems: A Thermochemical Assessment, Technical Report Series No.79, IAEA

Markin, T. L. \& McIver E. J. (1965). Thermodynamic and phase studies for plutonium and uranium -plutonium oxides with application to compatibility calculations, $3^{\text {rd }}$ International Conference on Plutonium 1965, p.p. 845-857

Markin, T. L. \& Street, R. S. (1967). The Uranium-Plutonium-Oxygen Ternary Phase Diagram, Journal of Inorganic and Nuclear Chemistry, Vol.29, pp.2265-2280

Naito, K.; Tsuji, T.; Ouchi, K.; Ouchi, K.; Yahata, T.; Yamashita, T. \& Tagawa, H. (1980). Electrical conductivity anomaly in near-stoichiometric plutonium dioxide, Journal of Nuclear Materials, Vol.95, pp.181-184

Nakamichi, S.; Kato, M. \& Tamura, T. (2011). Influences of Am and Np on oxygen potentials of MOX fuels, CALPHAD ; Computer Coupling of Phase Diagram and Thermochemistry, Vol.35, p.p. 648-651

Nakamura, A. \& Fujino, T. (1986). Thermodynamic analysis on point defects of $\mathrm{UO}_{2+x}$ at relatively small deviation from stoichiometry between 600 and $1400^{\circ} \mathrm{C}$, Journal of Nuclear Materials, Vol.140, pp.113-130

Sari, C.; Benedict, U. \& Blank, H. (1970). A Study of the Ternary System $\mathrm{UO}_{2}-\mathrm{PuO}_{2}-\mathrm{Pu}_{2} \mathrm{O}_{3}$, Journal of Nuclear Materials, Vol.35, pp.267-277

Sørensen, O. T. (1976). Thermodynamic Studies at Higher Temperatures of the Phase Relationships of Substoichiometric Plutonium and Uranium/Plutonium Oxides, Plutonium and Other Actinides 1975, pp.123-131

Sørensen, O. T. (1981). Nonstoichimetric Oxides, Academic Press, New York, p.p.1-59, 1981

Stan, M. \& Cristea, P. (2005). Defects and oxygen diffusion in $\mathrm{PuO}_{2-\mathrm{x}}$, Journal of Nuclear Materials, Vol.344, pp.213-218

Tetenbaum, M. (1974), High Temperature Vapourisation behaviour of Hypostoichiometric U-Pu-O and U-Nd-O Solid Solutions, Thermodynamics of Nuclear Materials, IAEA, Vienna, (1974) 305-320

Vasudeva Rao, P. R.; Bagawde, S. V.; Ramakrishna, V. V. \& Patil, S. K. (2006). Oxygen potential and thermal conductivity of $(\mathrm{U}, \mathrm{Pu})$ mixed oxides, Journal of Nuclear Materials, Vol.348, pp.329-334

Woodley, R. E. \& Adamson, M. G. (1985), The Oxygen potential of Near- and NonStoichiometric urania-25mol\% Plutonia Solid Solutions: A Comparison of Thermogravimetric and Galvanic Cell Measurements, Journal of Nuclear Materials, Vol.82, pp. 65-755 
Woodley, R. E. (1981), Oxygen Potentials of Plutonia and Urania Solid Solutions, Journal of Nuclear Materials, Vol.96, pp. 5-14 


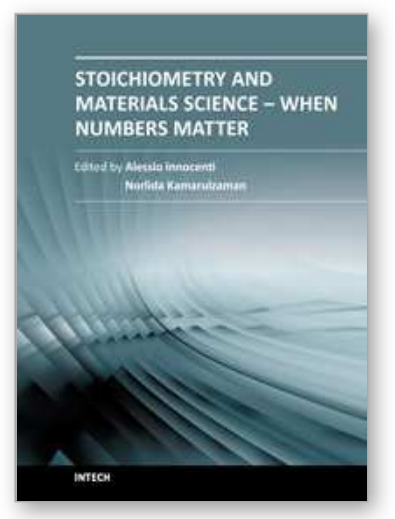

\author{
Stoichiometry and Materials Science - When Numbers Matter \\ Edited by Dr. Alessio Innocenti
}

ISBN 978-953-51-0512-1

Hard cover, 436 pages

Publisher InTech

Published online 11, April, 2012

Published in print edition April, 2012

The aim of this book is to provide an overview on the importance of stoichiometry in the materials science field. It presents a collection of selected research articles and reviews providing up-to-date information related to stoichiometry at various levels. Being materials science an interdisciplinary area, the book has been divided in multiple sections, each for a specific field of applications. The first two sections introduce the role of stoichiometry in nanotechnology and defect chemistry, providing examples of state-of-the-art technologies. Section three and four are focused on intermetallic compounds and metal oxides. Section five describes the importance of stoichiometry in electrochemical applications. In section six new strategies for solid phase synthesis are reported, while a cross sectional approach to the influence of stoichiometry in energy production is the topic of the last section. Though specifically addressed to readers with a background in physical science, I believe this book will be of interest to researchers working in materials science, engineering and technology.

\title{
How to reference
}

In order to correctly reference this scholarly work, feel free to copy and paste the following:

Masato Kato (2012). Oxygen Potentials and Defect Chemistry in Nonstoichiometric (U,Pu)O2, Stoichiometry and Materials Science - When Numbers Matter, Dr. Alessio Innocenti (Ed.), ISBN: 978-953-51-0512-1, InTech, Available from: http://www.intechopen.com/books/stoichiometry-and-materials-science-when-numbersmatter/oxygen-potential-and-defect-chemistry-in-nonstoichiometric-u-pu-o2

\section{INTECH}

open science | open minds

\author{
InTech Europe \\ University Campus STeP Ri \\ Slavka Krautzeka 83/A \\ 51000 Rijeka, Croatia \\ Phone: +385 (51) 770447 \\ Fax: +385 (51) 686166 \\ www.intechopen.com
}

\author{
InTech China \\ Unit 405, Office Block, Hotel Equatorial Shanghai \\ No.65, Yan An Road (West), Shanghai, 200040, China \\ 中国上海市延安西路65号上海国际贵都大饭店办公楼 405 单元 \\ Phone: +86-21-62489820 \\ Fax: $+86-21-62489821$
}


(C) 2012 The Author(s). Licensee IntechOpen. This is an open access article distributed under the terms of the Creative Commons Attribution 3.0 License, which permits unrestricted use, distribution, and reproduction in any medium, provided the original work is properly cited. 